\title{
Para pensar as compulsões contemporâneas: um estudo sobre privação e ideal do eu em Lacan
}

\section{To reflect about contemporary compulsions: a study of privation and ego ideal in Lacan}

\section{A pensar las compulsiones contemporáneas: un estudio acerca de privación e ideal del yo en Lacan}

\author{
Rogério Quintella* \\ Universidade Federal Fluminense - UFF, Niterói, Rio de Janeiro, Brasil
}

\begin{abstract}
RESUMO
Neste artigo, tomamos como objeto aprofundado de estudo a relação entre a privação e o ideal do eu, demonstrando-se que a primeira é a mola do segundo, a fim de se pensar as compulsões contemporâneas. Nelas o objeto simbólico, correspondente à privação, perde valor em privilégio do objeto real, trabalhado por J. Lacan. Esta análise parte dos constructos psicanalíticos de Freud e Lacan, bem como da ideia de queda dos ideais que aparece em autores contemporâneos como Zizek, Miller e outros. Demonstra-se aqui uma relação específica entre a privação e as psicopatologias da atualidade, especialmente as compulsões.
\end{abstract}

Palavras-chave: privação, Eu, objeto, compulsão.

\begin{abstract}
In this article, we take as deep study object the relation between privation and ego ideal, demonstrating that the first is the push of the second; to reflection about contemporary compulsion the former is the spring of latter. This study aims to comprehend more precisely about In these experiences the symbolic object, correspondent to privation, loses value in privilege of the real object, approached by Lacan (1995a). This analysis goes from the Freud and Lacan psychoanalytics conceptions, as well as from the idea of the ideals fall that are cited by contemporary authors, such as Zizek, Miller and others. We demonstrate a specific relation between privation and nowadays psychopathologies, specially compulsions.
\end{abstract}

Keywords: privation, ego, object, compulsion.

\section{RESUMEN}

En este artículo se toman en estudio objetar la relación entre la privación y el ideal del yo. Se muestra desde lo pensamiento de Lacan que la privación es impulso del ideal del yo. El estudio de la privación proporciona una lectura más precisa sobre las experiencias contemporáneas en el cual las compulsiones se evidencian. Ellos el objeto simbólico, correspondiente a la privación, pierde valor en el privilegio del objeto real. Este análisis es basado en las construcciones psicoanalíticas de Freud y Lacan y en la idea del ideal del yo evanescente, característica del sujeto contemporáneo, que aparece 
en autores contemporáneos como Zizek, Miller etc. Se muestra aquí una relación específica entre la privación y las psicopatologías de la actualidad, especialmente las compulsiones.

Palabras clave: privación, yo, objeto, compulsión.

\section{Introdução}

Falar de privação em Psicanálise requer que nos debrucemos sobre terrenos caros ao avanço das teses de J. Lacan. De fato, evocar o termo aqui em pauta implica, antes do mais, que se faça referência aos avanços da Psicanálise a respeito da teoria do objeto e dos percalços humanos em torno do corte constitutivo do ser perante a fala.

A análise aqui visada se pauta num recorte do conceito de privação, cuja referência é um objeto simbólico, mas que, num ponto específico, próprio de um processo defensivo, coloca o sujeito numa condição peculiar diante do denominado objeto real - objeto da necessidade em Lacan, ou melhor dizendo, da urgência, que aparece como impreterível no circuito da pulsão. Retomando a forma como o pensamento de Freud evoluiu, este exame será feito em consonância com a questão do excesso pulsional para pensar a privação, o ideal do eu e o supereu na clínica de hoje, em que a compulsão moral do supereu sobre o eu parece ser substituída (ou reatualizada na contemporaneidade) por uma compulsão ao objeto real. Veremos a especificidade desta lógica nas experiências de excesso atuais em que o chamado objeto real assume maior relevância, fazendo da compulsão ao consumo, às drogas, ao sexo, aos alimentos, etc. patologias que despontam na contemporaneidade.

Para o alcance desta questão, que será abordada ao final da presente exposição, faz-se necessária a exploração aprofundada do conceito de privação na teorização psicanalítica desde Lacan, doravante sua releitura do Édipo freudiano.

Lacan foi o pensador que, na tessitura do texto freudiano, com respeito à escuta psicanalítica, situou o mote a partir do qual o sujeito desbrava, em meio à travessia edipiana, o caminho para a sua dissolução. Já avançando com relação à teoria de Freud sobre o complexo de castração, Lacan abriu caminho, com o termo privação, a um novo circuito teórico para se pensar a mácula que se inscreve sob a insígnia do significante no universo da satisfação pulsional, possibilitando, também com isso, seu próprio avanço teórico e clínico. É o que Pellion (2007) salienta, como veremos, a respeito da teoria do real.

Visamos aqui tratar a privação a partir da qual a criança se dirige à imago paterna, na mira de sua figura ideal. Visamos também fomentar investidas e reflexões possíveis sobre os percalços 
neuróticos do sujeito naquilo que lhe carece como objeto, sua manque, falta-a-ser, falta de objeto, bem como do radical desmonte dos ideais na acepção do termo imago paterna, com respeito aos dias de hoje.

Para esta análise, percorreremos o caminho de Lacan especialmente no que diz respeito às três categorias de falta de objeto e necessariamente daquilo que perpassa a constituição do sujeito mediante a abordagem deste pensador sobre as diferentes dimensões que o complexo de Édipo assume na constituição do sujeito - seus três tempos. Com efeito, não se pode abordar a privação de maneira desatrelada da castração e da frustração, dado que é ali, nesta tríade, que Lacan avança na direção de se compreender a constituição do sujeito. E para não deixar à margem o rigor desta análise sobre a privação e seus destinos na contemporaneidade, torna-se substancialmente necessário expor essa tríade sob a lógica dos registros sustentados por Lacan ao longo de todo o seu ensino (imaginário, simbólico, real).

Se a privação é a mola do ideal do eu, como deixou evidenciado Lacan (1995b), o que pensar do esfacelamento do ideal na contemporaneidade? Não seria este um indício de novos destinos da relação específica do sujeito com a privação? Procuraremos expor algumas reflexões sobre esta questão, de modo a avançar nos estudos sobre a privação e acrescentar elementos que perfilam nossas indagações com respeito a este conceito (privação) na contemporaneidade.

\section{As Três Categorias de Falta: Castração, Privação, Frustração}

Lacan (1995a) aborda a questão da relação de objeto como estruturalmente faltosa, tal como se apreende de maneira quase trivial na acepção psicanalítica atual. Contudo, nada de trivial se constata quando se mergulha de maneira profunda no texto de Lacan. Busquemos articular esta condição faltosa do ser que, em se tratando de sujeito do inconsciente, mapeia sua trilha com respeito ao estatuto da alteridade que lhe é intrínseca.

Para Lacan não há no Outro nenhuma garantia sobre o bom encontro, dado que, fundamentalmente o que se acha envolvido na relação com este Outro é um encontro faltoso que marca a impossibilidade de acesso a um objeto ideal na experiência de satisfação.

Lacan aborda a castração como um conceito-chave para se pensar a constituição do desejo na cultura. Para isso lança mão da acepção freudiana (Freud, 1923/1996) de que é em torno da significação fálica que os dois sexos dinamizam sua condição faltosa perante a diferença. O falo é um significante capaz de dar significação para a diferença sexual (Lacan, 1995a). Mas não se reduz a isso. 
Nesse jogo da diferença, o falo se constitui como um objeto que se instaura como um terceiro elemento na relação amorosa eu-outro, mais além dela, funcionando como referência simbólica do objeto faltoso nessa relação. Com efeito, ele opera a sustentação de todo investimento da libido, que só encontra seu esteio de aplicabilidade mediante o dom, ou aquilo que acede ao nível do simbólico no investimento pulsional infantil, especialmente no que diz respeito à relação com a mãe.

Trata-se aí do amor como algo que se apresenta na dinâmica libidinal, em função do que não se tem, restando ao sujeito ofertar ao outro um "nada simbólico" que se transmite mediante objetos parciais envolvidos constantemente nesse dom. O falo é, para Lacan, o objeto dado pelo sujeito ao outro na experiência amorosa, é esse nada simbólico que só pode ser dado como dom, a partir do qual o sujeito reconhece sua própria castração, podendo dizer ao outro: "te amo, não sou completo e em você eu devo encontrar uma resposta sobre o meu próprio ser". No ato de amar sustenta-se ali mesmo a castração e o próprio desejo (Lacan, 2010). O falo é, assim, um significante cuja inscrição atualiza constantemente o objeto faltoso, a partir do qual o amor faz prevalecer a dádiva em torno desse "nada simbólico" que representa a castração e o motivo de todo investimento da libido. Nessa relação imaginária, a perspectiva do objeto em falta, na mãe, se consuma pela inscrição da castração simbólica. A castração é portanto simbólica, achando-se referida a um objeto imaginário, constatado primariamente pela criança na descoberta da diferença sexual.

Tal é o problema em torno do qual a criança estabelece sua posição subjetiva. A descoberta da diferença sexual se faz presente para o infante na forma do pênis que falta na mãe: objeto que dá esteio imaginário à falta estrutural inscrita na relação do sujeito ao significante. Trata-se aqui de fazer referência à condição da inscrição psíquica da diferença sexual que, já em Freud (1923/1996), se acha subssumida à primazia do falo para ambos os sexos. Trata-se também de situar o lugar que o desejo da mãe ocupa na dinâmica infantil em torno do objeto fálico (Lacan, 2005a).

$\mathrm{Na}$ relação imaginária mãe-criança, trata-se de uma referência à diferença sexual delineada por Freud (1923), na acepção infantil de que todos os seres humanos têm o pênis, com exceção das mulheres que não têm. $O$ falo da mãe, em falta, será então o elo identificatório inicial da criança que, na tentativa de recobrir a falta para complementar a mãe, posicionando-se como objeto do seu desejo, mantém o investimento da libido do eu e do objeto na relação mãecriança, operando-se contudo ali a marca da falta, cujo raio de abrangência vai além desta dualidade imaginária. Dito de outra forma, a criança se identifica inicialmente ao falo, ou seja, "se faz" de objeto do desejo da mãe, como tentativa fracassada de dar um esteio 
imaginário ao objeto em falta, ao qual a mãe dirige seu desejo, num mais-além da relação imaginária. Por isso a criança, por mais que deseje o desejo da mãe fazendo-se de falo para ela, encontra na própria mãe a privação como um referendo da falta no Outro, que a criança não pode suprir.

Nesse sentido, o desejo da mãe é o que se visa no conflito edipiano. Apoiado em Hegel (1992), Lacan sustenta a concepção do desejo como visada em direção ao próprio desejo, e não a um objeto natural ou instintivo. Se o desejo do homem é o desejo do Outro, como dizia Lacan (1997), trata-se do lugar a partir do qual o desejo se constitui como intrínseco ao deslizamento da cadeia significante na ordenação cultural cujo rastro é a perda do objeto, estruturante do fantasma. $O$ desejo da mãe é, com efeito, a visada da criança em torno da impossibilidade de agarrar o objeto da pulsão, tornando a relação ao Outro o próprio ponto de enlace do sujeito com sua castração simbólica.

Nessa dimensão, a privação na mãe é o que vem lembrar à criança de que há algo sempre além dela mesma que não se acha acessível na relação imaginária, inscrevendo-se como um "nada simbólico" para o qual a mãe dirige seu desejo. Este objeto do desejo da mãe é aquilo que ao mesmo tempo sustenta paradoxalmente seu investimento amoroso sobre a criança, já com a marca da falta ali inscrita e representada por um terceiro elemento nessa relação euoutro: o significante fálico.

Portanto, a relação de objeto não pode se referir, muito menos se reduzir, a uma filiação imaginária, porque o objeto que se simboliza como objeto faltoso no investimento amoroso infantil enuncia a condição da própria falta, na mãe, conflagrando o circuito do desejo como desejo do Outro (Lacan, 1995a).

Sendo assim, a castração é simbólica porque revela o significante da falta mais-além da imagem que se constata na diferença sexual diga-se de passagem, uma constatação nada fácil de resolver psiquicamente para o pequeno sujeito em vias de formação. $E$ a privação, sendo real porque solapa o sujeito diante da falta, se acha vinculada diretamente ao próprio objeto simbólico. Por este motivo mesmo Lacan enunciava a privação como sendo real e referida a um objeto simbólico. Dito de outra forma, a privação não é simbólica, dado que se trata de uma incidência real para o sujeito a respeito do objeto em falta no Outro, como um terceiro elemento na relação dual que possibilita a dialética na experiência do desejo: "ser ou não ser?", "ter ou não ter?" (Lacan, 1995b). A questão do ser e do ter, em torno da dialética desejante que produz a falta-a-ser (Lacan, 2005a) traduz-se por um conflito permanente em torno do qual o ideal do eu vai girar.

De fato, para a Psicanálise freudiana, repensada por Lacan, há algo que perpassa não apenas a relação imaginária eu-outro, mas também 
um elo de filiação referido ao objeto simbólico - o falo - como elemento de toda privação na dinâmica edipiana. Com efeito, a privação é central para os destinos da neurose, bem como da instauração do ideal do eu e da entrada do sujeito no denominado "período de latência".

Cabe, ainda, antes de mais nada, situar a dinâmica do sujeito frente aos três registros no que se refere à frustração. Esta é uma das formas como o sujeito vai experienciar a falta na relação com o desejo. Com efeito, Lacan reverbera que é com base na frustração de amor que a pulsão produz suas ressonâncias em torno do objeto real. A frustração é imaginária, evanescente e não estrutural. Ela é contingente na relação imaginária eu-outro, referindo-se, substancialmente, a um objeto real. Lacan percorre as trilhas da relação entre a pulsão e a necessidade, tratada como urgência (Dringlichkeit), para começar a dar corpo à sua concepção da falta de objeto sob o traçado da teoria pulsional freudiana.

No capítulo "A identificação ao falo" no seminário "A relação de objeto", Lacan (1995a) demonstra haver uma importante relação entre o objeto real e a pulsão na experiência da frustração, bem como na própria constituição do significante da falta.

Ali o autor discute sobre a questão da equivalência entre introjeção e projeção nas teorias da escola kleiniana - o que Lacan avalia como "abuso" teórico. O autor propõe um outro viés para abordar a introjeção e a constituição dos objetos pulsionais partindo da dimensão simbólica, raiz do signo de amor e do dom, assinalados como movimento que gira em torno da significação fálica, tal como salientamos. Apresentando sua teoria da frustração, demonstra que na raiz de toda introjeção também se acha modulada esta relação ao falo além da dualidade mãe-criança. É sob os auspícios da frustração de amor em função do desejo da mãe dirigido para um terceiro elemento nessa dualidade - o falo - que a criança se agarra ao seio, construindo 0 mundo dos objetos pulsionais, numa relação primordialmente intrínseca ao objeto da necessidade - o que Lacan denomina no Seminário 4 objeto real.

A questão do objeto real no Seminário 4 assume aqui toda relevância:

Cada vez que há uma frustração de amor, esta é compensada pela satisfação da necessidade. (...) um objeto real [seio, chupeta] assume sua função como parte do objeto de amor, e a pulsão se dirige ao objeto real como parte do objeto simbólico, este se torna, como objeto real, uma parte do objeto simbólico. (Lacan, 1995a, p. 178).

Tal é o eixo da metonímia na constituição do desejo a partir da falta, desenvolvida no ensino de Lacan. O pensador situa a distinção entre 
a necessidade e o desejo a partir da relação entre o objeto real, visado pela pulsão, e sua possibilidade de substituição com base no significante da falta. Essa relação entre objeto real e objeto simbólico assume relevância crucial na presente exposição, em função de uma peculiaridade na relação entre a privação e o ideal do eu. Contudo, para alcançarmos este ponto, é ainda imprescindível que se delineie a privação e o ideal do eu na lógica edipiana, tal como veremos a seguir.

\section{Da Privação ao Ideal do Eu na Lógica Edipiana}

A teoria freudiana avançou muito na segunda tópica em que se delineou tanto a pulsão de morte e os movimentos psíquicos além do princípio do prazer quanto as questões que envolvem a relação do sujeito com a cultura. Na segunda tópica, Freud vai além das questões relativas ao recalcado, passando a abordar os impasses do sujeito perante a impossibilidade de encontro com um objeto ou algo que the oferte a satisfação irrestrita, além de realizar uma análise aprofundada sobre o eu e os motivos de seus conflitos a partir do segundo dualismo pulsional.

Em "O futuro de uma ilusão", Freud (1927/1996) confere ao homem a condição da renúncia em nome de sua sobrevivência na civilização e de sua proteção perante o desamparo relativo à solidão, à doença, às ações perniciosas do outro e à própria morte. $O$ homem abre mão da satisfação irrestrita, trocando a liberdade total por uma parcela de segurança. Como corolário desta condição, a empreitada humana civilizatória vai encontrar, irremediavelmente a condição do mal-estar perante a exigência pulsional que permanentemente imprime sua força na direção da satisfação, sendo esta força intrínseca ao próprio circuito civilizatório. Tal como Freud (1930/1996) discorre em "Malestar na civilização", resta ao sujeito uma cota de prazer em função da configuração cultural, fazendo do desejo algo cujo destino cabe ao sujeito dar conta de maneira singular e radicalmente solitária.

De fato, foi de Freud que Lacan extraiu sua teoria das três formas de falta, não apenas como interpretação do texto freudiano, mas como extração mesmo, desenvolvida e aprofundada pelo pensador parisiense em torno dos três registros. As três formas de falta se acham explícitas no próprio texto "O Futuro de uma ilusão", onde Freud afirma: "Em benefício de uma terminologia uniforme, descrevemos como 'frustração' o fato de uma pulsão não ser satisfeita, como 'proibição' o regulamento pelo qual essa frustração é estabelecida, e como 'privação' a condição produzida pela proibição" (Freud, 1927/1996, p. 20).

Pode-se afirmar, portanto, o caráter fundamentalmente freudiano da teoria da falta em Lacan. Para Freud, a frustração aparece como uma 
variação das satisfações parciais em torno de uma proibição que é simbólica - a própria insígnia da castração - e se acha regulamentada nas leis da cultura impeditivas do acesso à satisfação irrestrita. Esse impedimento ou proibição não pode ser concebido simploriamente como extrínseco ao sujeito, ou um dado da civilização contra a "natureza humana". Isto é intrínseco à própria ordem cultural, a partir da qual a subjetividade humana se constitui.

Sobre a privação, Freud dirá que ela é a condição do homem perante a proibição cultural que o constitui em sua subjetividade mesma. 0 homem se acha terminantemente privado de acesso ao objeto do desejo do Outro, em função da interdição ao lugar do pai imposta pela cultura - marca da exogamia que implica o sujeito em sua castração e em sua condição desejante, impedindo permanentemente o sujeito de aceder ao denominado "gozo do Outro" (Lacan, 2010).

Desde o seminário 4, Lacan aborda estas questões evidenciando a especificidade da teoria freudiana sobre a falta de objeto e da exigência pulsional constante em torno desta falta. Lacan relaciona isto à travessia edipiana cujo traçado se faz valer pela triangulação familiar, via pela qual o sujeito se constitui. Para Lacan, esta travessia se dá em três tempos, cujo delineamento, desenvolvido no seminário 5 , proporciona importantes avanços, especialmente sobre a questão da privação e sua relação com o ideal do eu.

Lacan (1995b) salientava que o ideal do eu se constitui na passagem do segundo para o terceiro tempo edipiano. Se, no primeiro tempo do complexo de Édipo, trata-se da inscrição do simbólico como lei que vem substituir o significante materno (nome-do-pai), constituindo-se a Ordem Simbólica, no segundo, trata-se do pai imaginário (pai privador) como figura preferível à mãe na ordem familiar. Diante da lei simbólica, a criança se dirige à imago paterna buscando um esteio para a falta. Trata-se aí do pai como aquele que priva e que produz o elo de possibilidade de instauração do ideal do eu. Com efeito, a privação edipiana, em torno do objeto simbólico, é a mola para a formação do ideal do eu e para a saída do complexo de Édipo (Lacan, 1995b). No terceiro tempo o ideal do eu se consuma em torno do pai real que satisfaz sexualmente a mãe e supostamente detém o objeto de seu desejo - o falo. É na passagem do segundo para o terceiro tempo que o sujeito vai buscar uma identificação ao ideal à medida que o pai no terceiro tempo é aquele mesmo a quem supostamente pertence o falo e que abre caminho para o ideal do eu se consumar, promovendo-se ali o declínio do complexo de Édipo (Lacan, 1995b). Nesse processo de declínio do complexo de Édipo, a privação funciona como mola do ideal do eu. Lacan (1995b,) afirma: "(...) o nível da privação intervém na articulação do complexo de Édipo. Trata-se então do pai como aquele que se faz preferir em lugar da mãe, dimensão que vocês são absolutamente forçados a fazer intervir na função terminal, aquela que leva à formação do ideal do eu" (p. 178). 
Instaura-se a identificação ao ideal do eu numa "função terminal" que se ancora na imago paterna como figura "superior" e assimétrica, aquela que dirige, no imaginário, a introjeção dos traços e características do pai, bem como dos valores culturais nessa dinâmica identificatória.

Lacan (1995b) destaca que a passagem do segundo para o terceiro tempo, em que a privação conjuga a instauração do ideal do eu, introduz para o sujeito o chamado "período de latência:

Não quer dizer que o menino vai tomar posse de todos os seus poderes sexuais e exercê-los, como vocês bem sabem. Muito pelo contrário, ele não os exerce nem um pouco, e poderíamos dizer que, aparentemente, decai do exercício das funções que haviam começado a despertar (p. 201).

Com efeito, a ordem simbólica, inscrita no primeiro tempo, assume seu valor na passagem do segundo para o terceiro tempo, em que se instaura o ideal do eu e a criança passa a buscar uma forma de "ser" em função do ideal paterno. Toda esta análise vem atestar a importância de se refletir sobre os destinos da privação, dentre as demais formas de falta, na constituição do sujeito e da neurose. A privação assume função importante para a aceitação da perda do objeto, da impossibilidade de satisfação plena e da própria castração.

Se fizermos uma breve menção ao caso do pequeno Hans, por exemplo, podemos conceber que o menino fóbico nada mais faz do que tentar resolver sua questão com o pai privador. A lei já se acha inscrita, e sua presença é o que permite a Hans operar o deslocamento simbólico da figura do pai para a figura do cavalo. De fato, como Lacan salienta, o pai de Hans aparece como uma figura que, não obstante interditar o Outro materno, precariza sua privação à medida que a mãe não confere ao pai o lugar de exceção, deixando o peso de sua palavra a cargo do próprio menino. A fobia vem então tentar solucionar seu impasse entre aceitar a fantasia do parricídio ou salvar o pai desta última, perante a iminência da castração simbolizada pelo medo da mordida do Outro - o cavalo. Hans opera esta substituição inconsciente submetendo a função fálica à pulsão oral.

Lacan reverbera, então, que a privação é o elo da aceitação da lei, que conduz o sujeito à supressão ou dissolução do complexo de Edipo. O sintoma neurótico, referido ao ideal do eu no caso de Hans, vem assinalar que este mesmo ideal se acha calcado sobre uma imagem aterrorizante, e não sobre o referendo que a mãe institui perante o peso da palavra paterna.

A Psicanálise vem elucidar assim, com Lacan, a importância da abordagem do ideal do eu e da privação, no caminho nada fácil de construção da subjetividade na neurose. Não é por acaso que Freud 
desenvolve sua teoria da sexualidade, marcando, de forma certeira, a dimensão infantil como aquela que opera, fundamentalmente, o encontro com a falta, com a perda e mesmo com as mudanças pertinentes à passagem do tempo que implicam o caráter inalienável da finitude e da própria morte. Cabe aqui evidenciar então, no avanço da leitura psicanalítica, que o caminho aberto pela privação ao ideal do eu sustenta a possibilidade do luto do objeto perdido e da sustentação do desejo no caminho da constituição do sujeito. Tratamos de destacar em Lacan a figura do pai como ideal, não apenas como lei simbólica. E cabe salientar que o ideal do eu empurra a criança para fora da organização edipiana, acelerando sua destruição.

Cabe evocar ainda a afirmação de Freud (1919/1996) de que, na identificação, o eu é o resultado de um precipitado de investimentos primários abandonados. Identificando-se ao seu ideal e buscando uma forma de ser para além do eu como um "narciso desamparado", o precipitado de identificações supera a imagem narcísica conflagrada na megalomania infantil. Com efeito, este caminho percorrido pela criança implica que ela abandone seus investimentos primários, lançando-se à imago paterna como saída preferencial ao desejo da mãe - não obstante isto ter como pano de fundo a visada impossível de ocupar o lugar do pai. Interditada de assumir este lugar, resta à criança fazer o luto do objeto, aceitando-se como desejante. O ideal do eu, com todos os seus paradoxos, sustenta, a partir da privação, o caminho para este abandono, bem como para a instauração do luto.

O luto é um trabalho de simbolização; ele visa dar ao perdido um lugar simbólico e tem como resultante uma modificação no eu mediante a identificação aos traços do ideal. Não é por acaso que, após o luto, o sujeito não é mais o mesmo, tal como Lacan (2005a) assinala, fazendo daquele um meio pelo qual o eu inscreve seu caráter de impermanência e transitoriedade. Esta condição se instaura à medida que o sujeito busca na imago paterna - o pai que priva - um esteio identificatório capaz de dar suporte e abrir caminho para novos investimentos objetais. E Lacan (1995b,) afirma: "(...) toda privação real exige simbolização" (p. 191). Isto se refere à mobilização do luto: de um lado o luto do objeto, ancorado no ideal do eu; de outro lado, o luto do próprio pai ideal, já que o pai, no real, é incapaz de garantir o sucesso das empreitadas amorosas do sujeito, muito menos do seu ser, cabendo ao próprio sujeito o papel de desejar perante a inescapável condição faltosa e transitória do ser.

Trata-se de destacar, assim, esta relação intrínseca da privação com a formação do ideal que promove o elo de sustentação do desejo na direção de sua própria condição finita, sexuada, transitória, mortal.

Toda esta análise implica a distinção entre supereu e ideal do eu. Enquanto o ideal do eu é o ponto de enlace do sujeito com a identificação secundária dirigida à imago paterna que norteia a busca 
por um objeto substitutivo na cultura, o supereu é força que irrompe na direção do gozo absoluto, além do princípio do prazer, marcando ali, ao mesmo tempo, sua impossibilidade e proibição (Lacan, 2010).Veremos adiante como isso se evidencia, especialmente quando o que está em questão é o supereu na dinâmica da privação.

\section{Privação, Ideal do Eu e Supereu}

Pellion (2007) nos traz uma problematização em torno das três categorias de falta, demonstrando haver, já no seminário 4, a partir do termo privação, a abertura do caminho para a invenção do objeto a na teorização de Lacan (2010). Pellion discute sobre o caráter real da privação, indagando como o sujeito, efeito do discurso, apreende este furo real, à medida que ele não se faz representar para o próprio sujeito, por se caracterizar como real, e não simbólico, nem imaginário. De fato, o autor demonstra que, em Lacan, a privação só pode ser empreendida para um sujeito que articule algo no plano simbólico, ou seja, esta falta só pode ser formulada no lugar do Outro, como insígnia do real no Outro. E, por mais que o furo real exija um objeto simbólico, isto faz da própria teoria do falo algo ainda insuficiente para abordar a falta real à qual o próprio Lacan se refere no Seminário 4 como privação. Não obstante isto, Pellion defende que a teoria do objeto a como extração, no Outro, do objeto em falta, só poderia ter sido concebida a partir deste impasse colocado pelo termo privação real, preludiando-se ali o avanço teórico de Lacan na invenção do objeto $a$, a partir da profunda exploração introduzida por este mesmo pensador em torno da teoria da falta.

Esta ponderação de Pellion enriquece a análise aqui proposta em torno da relação entre o ideal do eu e a privação, a partir dos avanços do pensamento psicanalítico. De fato, se toda privação exige simbolização, exigindo que se articule algo no registro simbólico, é porque neste mesmo registro se acha inscrita, para o sujeito, a impossibilidade da cadeia significante representá-lo plenamente, a partir do que se produz, de um lado, o sujeito como "falta-a-ser", de outro lado, um resto não simbolizado que Lacan (2005b) denomina objeto $a$. Duas funções reais que compõem a estrutura do fantasma em torno da perda fundamental, causa de desejo. Concebido como objeto extraído na relação ao Outro, o pequeno a se produz pelas sucessivas perdas na experiência de satisfação - o olhar, a voz, o seio, as fezes - cuja marca inclui desde já as idas e vindas do investimento objetal na relação dual infantil. Cabe dizer que este resto retorna para o sujeito em diferentes aspectos de sua vida subjetiva. 
A voz, por exemplo, como objeto a extraído do Outro, retorna para o sujeito como uma outorga interna oriunda de uma exigência massacrante em torno da falta-a-ser.

Foi Freud quem abriu o caminho para estas considerações sobre a exigência de ser na subjetividade humana, imprimida pelo supereu em função do ideal. Na acepção de Freud, o supereu aplica sua exigência em torno da imago paterna - aqui novamente evocada - à medida que a voz superegóica outorga o empuxo ao lugar do pai: "Você deve ser igual a seu pai". Voz que enuncia, no seu próprio eco, a interdição: "Você não pode ser igual a seu pai, pois certas coisas são prerrogativas dele" (Freud, 1919/1996, p. 47). Neste patamar, o massacre do supereu, não obstante funcionar em torno do ideal, toca o real.

Tal exigência em torno da falta-a-ser deflagra aquilo que o próprio significante deixa como marca indelével ao representar o sujeito: não há, no Outro, um significante que represente plenamente o sujeito e ofereça uma garantia sobre o seu ser, o que faz do Outro um sistema claudicante cuja falha é o próprio fundamento do sujeito e do desejo. Lacan (2005a) afirma: Não há no Outro nenhum significante que possa no caso responder pelo que sou" (Lacan, 2005a, p. 46-47).

Lacan (2002) distingue o sujeito do ser, ao abordar o desejo, afirmando: "o desejo é a metonímia do ser no sujeito: e o falo é a metonímia do sujeito no ser" (p. 35). Ou seja, por mais que o significante venha tentar representar, quer o sujeito, quer o objeto, ele fracassa em sua função. O significante, como única via do sujeito para se fazer representar na cadeia simbólica, deixa o rastro da falta, produzindo o objeto perdido inapreensível na metonímia desejante. Instaura-se, com isso, a constatação do próprio sujeito do inconsciente de que o objeto se acha perdido no deslizamento da cadeia significante. Na busca pelo objeto perdido, a cada significante, o sujeito constata: "não é o objeto", repetitivamente, em série (o desejo é a metonímia do ser no sujeito), tornando permanente o desejo. Da mesma forma, o sujeito, como efeito do significante, está sempre aquém de apreender uma verdade última sobre seu próprio ser no universo das palavras, o que produz uma falta-a-ser empreendida pela castração: "não sou", repetitivamente, em série (o falo é a metonímia do sujeito no ser). Onde penso a mim mesmo, não sou, e sou onde não penso nem posso falar, dado que o ser se acha do lado do objeto e do gozo, e não do sujeito, na estrutura fantasmática.

O que vem responder a esta privação real do ser como marca da falta no Outro que fundamenta o sujeito? Entendemos que o que vem responder a isso, a partir da leitura do próprio Lacan, seja o ideal do eu como "formatação" no Outro de uma tentativa de ser. Exigência cujo apoio se dará em torno do ideal, mas não sem a própria insígnia 
do objeto perdido como resto não simbolizado na operação da palavra em torno do infantilismo sexual, por meio da voz.

Sendo assim, isto não pode ocorrer fora do plano da privação que, ao fomentar no sujeito a formação do ideal do eu, ao mesmo tempo é a impressão no Outro do furo real, fazendo do sujeito um ser em falta manque: um sujeito "manco", claudicante, que se expõe à tirania do supereu em torno do ser. Isto redunda num massacre do supereu que, perante o ideal, imprime seu sadismo sobre o eu, culpabilizando-o por sua necessidade de punição em torno do ideal de perfeição e satisfação absoluta, bem como empurrando o sujeito, paradoxalmente, para esta condição absoluta do ser e do gozo. Nesta apreensão, o supereu imprime sua força sádica mediante 0 imperativo de ser, de gozar (Lacan, 2010) e, com isso, de aniquilar a função do próprio sujeito, qual seja, a de desejar, acelerando o encontro com a morte.

\section{Para Encaminhar: Privação, Ideal do Eu e as compulsões contemporâneas}

A análise aqui realizada se acha intimamente implicada em nossa investigação sobre os destinos da privação e do ideal do eu na contemporaneidade. Como dissemos no início desta exposição, evidencia-se na atualidade um desmoronamento do ideal na relação do sujeito com o gozo e com o desejo (Quintella, 2014; Machado, 2005). Miller (2004) sinaliza a forma como o sujeito lida com o gozo na atualidade, tratando-o pelo termo "sujeito desbussolado". Contudo o que se constata é que esse desbussolamento assume diferentes contornos na atualidade, especialmente na relação ao ideal. $\mathrm{Na}$ modernidade, tratava-se de um sujeito que contesta o ideal e busca rechaçar a falta com o sintoma. Na atualidade, o sujeito se acha cada vez mais "desbussolado", dado que os modelos ideais são fugazes e o ideal do eu não assume seu papel de sustentar um norteador para o desejo, fazendo da ordem simbólica algo constantemente pronto a ser deixado à margem.

Sobre isso cabe salientar que, à medida que a ordem simbólica se organiza na travessia da lógica infantil, especificamente no primeiro tempo do complexo edipiano, se mapeia para o sujeito um ideal do eu pautado na figura daquele que sustenta a coesão identificatória na família. É de se considerar que as análises de Freud (1930/1996) em torno da autoridade, bem como da agressividade infantil dirigida a ela, emerge num tempo ulterior à inscrição do sujeito na ordem simbólica. Como dissemos, na passagem do segundo para o terceiro tempo, trata-se da instauração do ideal do eu que confere o valor da ordem simbólica inscrita no primeiro tempo. 
É importante refletir sobre os destinos da ordem simbólica e da privação na relação com o desejo, se levarmos em conta a condição extremamente evanescente do ideal na experiência do sujeito hoje. Se o ideal do eu não funciona mais como antes, trata-se de pensar a passagem do segundo para o terceiro tempo edipiano, ali onde se instaura a privação que abre caminho para a identificação ao ideal do eu.

Isto diz respeito a uma condição em que a criança, por motivos defensivos, não credita ao pai a posse do falo nessa passagem, impedindo-se de se lançar ao ideal do eu, ou ao pai imaginário como preferível às moções pulsionais dirigidas à mãe. Ou seja, trata-se de uma mudança na relação com a autoridade parental nos dias de hoje. É na medida em que o pai não é colocado na posição de privador que o ideal do eu evanesce. Nesse patamar, há uma forma distinta do sujeito dar destino à privação, fazendo com que o ideal do eu se constitua de maneira cada vez mais evanescente. É crucial que se definam os parâmetros de análise sobre a constituição do ideal do eu e a identificação na relação à autoridade parental em função da privação. O sujeito de hoje apresenta predominantemente em seu discurso uma dificuldade de dinamizar afetos que de outra sorte seriam capazes de superar as representações primárias da constituição do eu ideal, subjugado à experiência jubilosa do narcisismo. Trata-se nesse contexto de uma fugacidade na identificação secundária que não pinça o Pai como figura central dessa identificação na organização sócio-familiar de hoje, assinalando-se uma condição peculiar frente a essa fugacidade identificatória.

O que se localiza nesse nível é uma ruptura precoce com o pai ideal, à medida que este não se apresenta como figura de autoridade a partir da qual o sujeito buscará identificação. Trata-se nesses casos de uma recusa do ideal, em que a criança, ao invés de virar as costas ao complexo de Édipo, ali se mantém, num movimento que retroage para a privação, soerguendo-se nesses casos uma defesa contra a própria privação e a castração. Percebe-se esta lógica em diversos fenômenos clínicos em torno de experiências de excesso, de compulsões e satisfações imediatistas.

Algo se passa entre a frustração e a privação que impele o sujeito ao objeto real. Isto se manifesta na forma de experiências de excesso em torno da compulsão ao consumo, às drogas, aos alimentos, etc. Ali, a busca pelo objeto primário da necessidade reduz o dom à urgência, e o sujeito se impele ao encontro inadiável e impreterível com objetos de consumo. Trata-se de uma privação "desmentida", um desmentido da privação (Quintella, 2016) como se o sujeito não estivesse privado de nada e pudesse tudo: como se pudesse recuperar, de fato, o objeto perdido, supostamente exposto nos círculos sociais. Esta condição se constitui em torno de uma urgência 
em direção ao objeto real em que o sujeito, diante da frustração, desmente a privação. Trata-se de uma forma de defesa contra a castração e de uma tentativa desesperada de agarrar o objeto para dar estofo à introjeção no lugar do ideal do eu.

Não obstante se aproximar da perversão, essas experiências se acham inscritas no registro da neurose. Com efeito, diferentes modos de compulsão podem aparecer na perversão, mas há casos de neurose em que se verifica um impulso em direção ao objeto real, diferente do cálculo perverso (no qual se acha fundado o desmentido ou recusa da castração). Nas condições referidas à compulsão na neurose se trata de experiências de excesso que, dando a impressão de uma perversão, revelam um regime organizado em torno do recalque e não da recusa à castração. Se há uma recusa, ela se dá em torno do ideal, da privação, e não da lei simbólica.

Cabe considerar o papel do supereu nessas experiências, dado que este opera sua força de maneira desatrelada do ideal do eu nesses casos. Isto evidencia uma diferença entre o sujeito da clínica de Freud e o sujeito contemporâneo.

Lacan (1995a) já enunciava o que o próprio Freud salientou em torno dos investimentos primários:

$\mathrm{Na}$ medida em que a regressão ao objeto oral primitivo de devoração vem compensar a frustração de amor, essa reação de incorporação (...) é a incorporação de certas palavras que está na origem da formação precoce daquilo a que se chama o supereu (Lacan, 1995b, p. 178).

Lacan salientava que o objeto real "vem substituir a frustração de amor" (Lacan, 1995a, p. 178). E mais: o supereu para Lacan é análogo ao objeto real, à medida que substitui a frustração de amor, operando seu massacre moral sobre o eu em função do ideal na relação amorosa infantil.

Se o supereu é análogo ao objeto real, sua força se imprime em direção ao eu justamente porque o ideal do eu vem substituir o empuxo ao gozo pela identificação. É sob a insígnia da privação que o ideal do eu vai se levantar, fazendo com que o supereu atue em função deste último. Na época de Freud, o que se evidenciava com maior frequência, portanto, era um supereu que tomava o eu como objeto de massacre em função do ideal.

Hoje, a evanescência dos ideais produz como corolário, muitas vezes, experiências de excesso em que o supereu, ao invés de tomar o eu como objeto de seu sadismo (em função do ideal do eu), dirige sua força ao objeto real da necessidade, tal como uma urgência de gozo que reduz o objeto simbólico à urgência primária como dissemos, cabendo ressaltar que, como dizia Lacan, o supereu é análogo ao objeto real em face da frustração de amor (Lacan, 1995a). Dado o 
esfacelamento dos modelos ideais, bem como a fugacidade identificatória ao ideal do eu, o empuxo superegóico se dirige ao objeto real da urgência infantil na forma da compulsão. A privação, como elo edipiano para a emergência do ideal do eu, fica rechaçada sob as determinações da compulsão ao objeto real.

Nesses casos, o objeto simbólico, correspondente à privação, perde valor, assim como o dom. Ali o sujeito se atira ao objeto real, como um impulso impreterível a satisfações diretas, sem contornos simbólicos, na forma da compulsão. Não é por acaso que, nessas patologias, o amor tende a evanescer, ficando o sujeito atado a uma relação direta com o objeto da necessidade. Tal é o passo, aqui introduzido, doravante o aprofundamento das questões que giram em torno do termo privação.

Estas considerações evidenciam desde já a necessidade de se estabelecer uma discussão sobre o caráter fundante da ordem simbólica, de maneira a pensá-la perante o chamado do "declínio do pai" (Zizek, 2016), hoje intensamente discutido no meio psicanalítico. Tratamos deste declínio do pai, aqui, na acepção de sua imago, não referendando-se a ideia de "falência do simbólico". Trata-se de um declínio da autoridade, daquela imagem patriarcal na família que, com a queda do antigo regime e do poder clerical sobre a organização social e regimental, passa a ser desvalorizada e preterida, fazendo do ideal do eu, na família, algo fugaz. Talvez resida aí um caminho para se buscar o avanço da pesquisa psicanalítica sobre a função do falo na instauração do ideal do eu e seu destino na neurose contemporânea. Não se trata, portanto, de tratar das questões atuais abrindo mão do arcabouço teórico freudiano em torno da estrutura edipiana, mas de buscar subsídios para pensar suas nuances diferenciais na atualidade.

O declínio paterno se estabelece, portanto, ao nível de sua imago no âmbito social e familiar, tal como Lacan já apontava a respeito dos complexos familiares. Muito antes de teorizar sobre o simbólico, Lacan já dizia que a Psicanálise é efeito de um "declínio social da imago paterna" (Lacan, 2003, p. 67) e de uma crise psicológica que se acha na raiz do ato de fundação da Psicanálise desde Freud. Com sua teorização a respeito da tríade imaginário, simbólico e real, fica evidenciada a necessidade de se distinguir o pai enquanto lei, que funda a ordem simbólica, do pai enquanto figura na família e na sociedade, que abre caminho para o ideal do eu. A imago paterna é algo que emancipa o caminho para a saída do Édipo, localizando-se entre o simbólico e o imaginário. Ou seja, a ordem simbólica, inscrita no primeiro tempo edipiano, ganha seu valor no terceiro tempo, ao nível da relação à autoridade paterna e da identificação ao ideal do eu. Diante da evanescência e da fugacidade identificatória ao ideal, a ordem simbólica perde valor, e o sujeito se desnorteia no caminho para a satisfação, os investimentos amorosos, o desejo. Esta 
condição afasta o sujeito das referências à metáfora, à poesia, à simbolização, ao devaneio, ao luto, etc. Ou seja, não obstante inscrita, possibilitando estruturalmente a substituição do objeto e a ascensão do dom na relação amorosa, a ordem simbólica perde seu valor e o sujeito se afasta, nos meios sociais, desta possibilidade de metaforização. Não sendo nem psicótico, nem perverso, esses sujeitos neuróticos muitas vezes parecem refratários ao dispositivo analítico de maneira mais contundente, em que a passagem ao ato passa a ser, frequentemente, a via pela qual o sujeito encontra uma forma de lidar com o excesso pulsional.

Portanto, se o sujeito é efeito de uma falha no simbólico (Lacan, 1992) não se trata de evidenciar uma mudança na ordem simbólica, ou na chamada função paterna. Isto não muda, é estrutural, e a cultura continua operando seus efeitos de constituição dos laços sociais. O que é novo é a posição do sujeito perante a falha no simbólico e a privação real, enunciando-se a possibilidade do sujeito engendrar outros tipos de negação e defesa distintos daqueles que preponderavam na época de Freud (autor, 2016).

Este trabalho não visa o esgotamento das questões que envolvem a privação e o ideal do eu, tampouco, muito menos, os efeitos de sua evanescência e a forma como o sujeito contemporâneo lida com a privação. Visamos aqui abrir caminho para novas empreitadas teóricas mediante o aprofundamento do estudo psicanalítico sobre a privação como uma das formas de falta. Deste modo, buscamos evidenciar a importância de sua relação com o ideal do eu, bem como a necessidade de investigação aprofundada em torno desta temática, dado que ela se evidencia como crucial para a abordagem do sofrimento contemporâneo. Visamos então, com a exposição aqui realizada, traçar elementos que consideramos importantes para a reflexão psicanalítica contemporânea que, a nosso ver, não pode deixar de passar pela análise detida da privação e do ideal do eu na constituição do sujeito e das saídas psicopatológicas que envolvem tais problemáticas atuais.

\section{Referências}

Freud, S. (1913/1996). Totem e tabu. In: Freud, S. Edição Standard Brasileira das obras Psicológicas Completas de Sigmund Freud, volume 13 (pp. 11-125). Rio de Janeiro: Imago.

Freud, S. (1914/1996). Sobre o narcisismo: uma introdução. In: Freud, S. Edição Standard Brasileira das obras Psicológicas Completas de Sigmund Freud, volume 14 (pp. 77-110). Rio de Janeiro: Imago.

Freud, S. (1923/1996). A organização genital infantil: uma interpolação sobre a teoria da sexualidade. In: Freud, S. Edição 
Standard Brasileira das obras Psicológicas Completas de Sigmund Freud, volume 19, (pp. 157-164). Rio de Janeiro: Imago.

Freud, S. (1927/1996). O futuro de uma ilusão. In: Freud, S. Edição Standard Brasileira das obras Psicológicas Completas de Sigmund Freud, volume 21, (pp. 15-66). Rio de Janeiro: Imago.

Freud, S. (1930/1996). Mal-estar na civilização. In: Freud, S. Edição Standard Brasileira das obras Psicológicas Completas de Sigmund Freud, volume 21, (pp. 73-150). Rio de Janeiro: Imago.

Freud, S. (1933/1996). Novas conferências introdutórias sobre Psicanálise. In: Freud, S. Edição Standard Brasileira das obras Psicológicas Completas de Sigmund Freud, volume 22, (pp. 17180). Rio de Janeiro: Imago.

Hegel, G.W.F. (1992). Fenomenologia do espírito - parte I. Petrópolis: Vozes.

Lacan, J. (1992). O seminário, livro 17: o avesso da Psicanálise. Rio de Janeiro: Jorge Zahar.

Lacan, J. (1995a). O seminário, livro 4: a Relação de objeto. Rio de Janeiro: Jorge Zahar.

Lacan, J. (1995b). O seminário, livro 5: as formações do inconsciente. Rio de Janeiro: Jorge Zahar.

Lacan, J. (1997). O seminário, livro 7: a ética da Psicanálise. Rio de Janeiro: Jorge Zahar.

Lacan, J. (2003). Os Complexos Familiares na formação do indivíduo. In: Outros Escritos (pp. 29-90). Rio de Janeiro: Zahar.

Lacan, J. (2002). O desejo e sua interpretação. Porto Alegre: Associação Psicanalítica de Porto Alegre, publicação não comercial.

Lacan, J. (2005a) Textos psicanalíticos I - Hamlet por Lacan. São Paulo: Escuta/ Liubliú.

Lacan, J. (2005b) O Seminário, livro 10: a angústia. Rio de Janeiro: Jorge Zahar Editor.

Lacan, J. (2005c) Nomes-do-Pai. Rio de Janeiro: Jorge Zahar.

Lacan, J. (2010). Encore. Rio de Janeiro: Escola de Psicanálise Letra Freudiana.

Machado, O. M. R. (2005). A clínica do sinthoma e o sujeito contemporâneo. Tese de Doutorado. Universidade Federal do Rio de Janeiro. Rio de Janeiro, RJ, Brasil.

Melman, C. (2003). O Homem sem gravidade: gozar a qualquer preço. Rio de Janeiro: Companhia de Freud.

Pellion, F. (2007). Objeto a e privação. Um caso de retroação significante na teoria psicanalítica. Ágora: Estudos em teoria psicanalítica, 10, 203-210.

Quintella, R. (2014). As funções do pai: pensando a questão da autoridade na constituição do sujeito contemporâneo a partir de 
um estudo psicanalítico do ideal do eu. Revista Subjetividades, 14, 291-303.

Quintella, R. (2016). O desmentido da privação na atualidade. Ágora: Estudos em teoria psicanalítica, 19, 115-130.

Zizek, S. (2016). Édipo: para onde? In: O sujeito incômodo - o centro ausente da ontologia política. (pp. 329-412) São Paulo: Boitempo.

\section{Endereço para correspondência}

\section{Rogério Robbe Quintella}

Universidade Federal Fluminense - UFF

Rua Miguel de Frias, 9, Icaraí, CEP 24220-900, Niterói - RJ, Brasil

Endereço eletrônico: rrquintella@hotmail.com

Recebido em: 20/08/2015

Reformulado em: 15/01/2017

Aprovado em: 27/04/2017

\section{Notas}

* Professor Adjunto do Departamento de Psicologia da Universidade Federal Fluminense. Doutor em Teoria Psicanalítica pela Universidade Federal do Rio de Janeiro. Editor-executivo da Revista ECOS - Estudos Contemporâneos da Subjetividade. 